\title{
SYNERGETIC USE OF THE SENTINEL-2, ASTER, AND LANDSAT-8 DATA FOR HYDROTHERMAL ALTERATION AND IRON OXIDE MINERALS MAPPING IN A MINE SCALE
}

\author{
Mohammad KHALEGHI ${ }^{1)}$, Hojjatolah RANJBAR ${ }^{2)}$, Ali ABEDINI ${ }^{1)}$ * \\ and Ali Asghar CALAGARI ${ }^{3)}$ \\ 1) Department of Geology, Faculty of Sciences, Urmia University, 5756151818 Urmia, Iran \\ 2) Department of Mining Engineering, Shahid Bahonar University of Kerman, 7616914111, Kerman, Iran \\ ${ }^{3)}$ Department of Earth Sciences, Faculty of Natural Sciences, University of Tabriz, Iran
}

*Corresponding author's e-mail: abedini2020@yahoo.com and a.abedini@urmia.ac.ir

\begin{tabular}{l} 
ARTICLE INFO \\
Article history: \\
Received 1 May 2020 \\
Accepted 17 July 2020 \\
Available online 20 August 2020 \\
\hline Keywords: \\
Sentinel-2 \\
Landsat-8 \\
Gossan zones \\
ASTER \\
Hydrothermal minerals \\
DPCA \\
MTMF \\
\hline
\end{tabular}

\begin{abstract}
Many of the known Tertiary porphyry $\mathrm{Cu}$ deposits (PCDs) are situated in the Central Iranian Volcanic Belt (CIVB). The study area is located in the southern part of the CIVB and southern part of the Kerman Cenozoic magmatic arc. This research highlights the significance of the synergetic use of operational land imager aboard the Landsat-8 (OLI), Sentinel-2, and advanced space-borne thermal emission and reflection radiometer (ASTER) data for exploration of copper mineralization in a mine scale. Multispectral images in the visible and near infrared bands of $(0.45-$ $1.0 \mu \mathrm{m})$ the OLI and Sentinel-2 were used to identify the gossan zones. ASTER short wave infrared (SWIR) data with the wavelength between 1.65 and $2.43 \mu \mathrm{m}$ were used for mapping hydrothermal alteration zones. Laboratory spectra obtained from minerals such as muscovite and illite (phyllic alteration), kaolinite and montmorillonite (argillic alteration), epidote and chlorite (propylitic alteration) were applied in mixture tuned matched filtering (MTMF) algorithm on the ASTER data to enhance the existence of these minerals. The spectra of the index minerals from each alteration type were used in this algorithm and the abundances of minerals in the MTMF image were rescaled to be within the ranges of 34-54\%, 54-74\% and 74-100\%. The studied mineralized zone is associated with the iron rich phyllic and argillic hydrothermal alteration types which can be best detected by using integrated ASTER, OLI, and Sentinel-2 images. The diamond drill cores data also indicate that copper is more enriched below the gossan zones. The gossan index minerals (GIM) including goethite, jarosite, and hematite were identified by X-ray diffraction (XRD) method, spectral analyses, and petrographic examinations. The Sentinel -2 data proved to provide remarkably better mapping result for iron oxide minerals than the OLI and ASTER data. The directed principal component analysis (DPCA) method, In the data of the Landsat- 8 and Sentinel2 were used for mapping of the gossan index minerals such as goethite, jarosite and hematite and the argillic, phyllic and propylitic hydrothermal alteration types were enhanced using the MTMF methods. The hydrothermal alteration pattern and the distribution of the gossans in the study area show a porphyry-type mineralization. This study showed that the synergetic use of different satellite images with different spatial and spectral resolutions can be used for mineral exploration in a large scale. The use of laboratory spectra obtained from hydrothermal alteration minerals in MTMF method depicts that the alteration minerals were mapped more accurately relative to those MTMF images that are derived from standard spectral libraries. The samples collected from the surficial hydrothermal alteration zones as well as diamond drill cores showed that the copper mineralization occurres mainly along the border of the phyllic and argillic alteration zones, and the magnetite mineralization in the propylitic zone.
\end{abstract}

\section{INTRODUCTION}

Central Iranian volcano-plutonic copper belt is well known for having a great potential for the Cenozoic porphyry copper mineralization. The Kerman Cenozoic magmatic arc (KCMA) is located in the southeastern part of this belt (Alavi, 1994). The study area is located in the southern part of the KCMA. There are several mineralized prospecting areas within the KCMA including the Zamin-Hossein copper mine. For this reason, areas with hydrothermal alteration were chosen for remote sensing studies (Fig. 1). So far, substantial studies on mineralization and regional alteration have been carried out in this area implicating that it deserves more detail works (Khaleghi et al., 2014; Hosseinjani Zadeh and Honarmand, 2017).

Porphyry copper deposits are large rock mass that are associated with intermediate to felsic hypabyssal porphyritic intrusive rocks (Chiaradia and Caricchi, 2017). These deposits contain disseminated chalcopyrite and other sulfide minerals (Liu et al., 2020). They show hydrothermal alteration zonation that start with potassic alteration at the center and while 


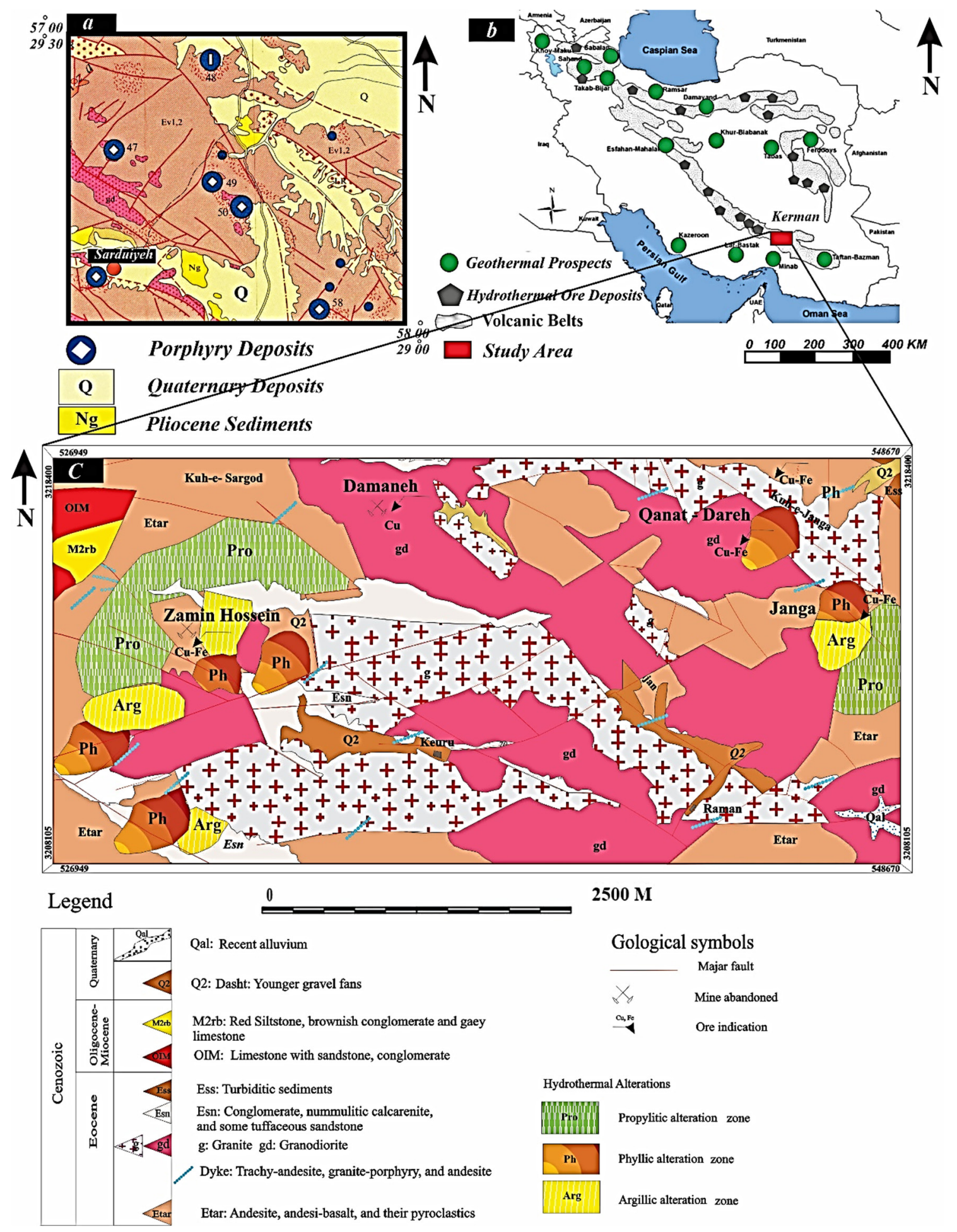

Fig. 1 (a) Simplified geological map of the Bahr-Aseman area (compiled from Dimitrijevic, 1973). Location of the Sarduiyeh area is also shown. (b) Location of the study area in an index map of Iran. (c) Geological Map of the Zamin Hossein (modified after Zolnaj et al., 1956).

moving outside we come across phyllic, argillic and propylitic hydrothermal alteration types (Lowell and Guilbert, 1970). Each hydrothermal alteration zone contains minerals with spectra characteristics that can be used for their enhancement by applying remote sensing techniques. The spectral features of the index minerals such as illite-muscovite, kaolinite - montmorillonite, and epidote-chlorite are used for mapping the hydrothermal alteration zones (Hosseinjani Zadeh and Honarmand, 2017).

Gossan is the name given to a large mass of residual $\mathrm{Fe}$ oxy-hydroxide material formed by oxidation of Fe-bearing sulfide ore deposits. The process of gossan formation starts with oxidation of 
pyrite and other sulfides to form Fe oxy-hydroxides plus sulfuric acid. The initial product of weathering is typically an amorphous ferric hydroxide $\left[\mathrm{Fe}(\mathrm{OH})_{3}\right]$ which by aging gradually crystallizes to limonite, goethite, and hematite. Other important associated minerals with the Fe-oxides are jarosite, gypsum, and silica (Atapour and Aftabi, 2007). Customarily, Feoxide zones are developed over many of the porphyry bodies (Azizi et al., 2010). A gossan may be indicating feature for the presence of a porphyry copper deposit (PCD) hidden below the surface, and the spatial distribution of gossan minerals are especially important in exploring for this type of deposits (Atapour and Aftabi, 2007). The sentinel-2 mission is an earth observation system developed by the European space Agency (ESA) which covers latitudes between $-56^{\circ}$ and $+48^{\circ}$ with a swath width $290 \mathrm{~km}$ and consist of two indentical satellite Sentinel-2A and Sentinel-2B (Tangestani and Shayeganpor, 2020). The Sentinel-2 has several bands that cover iron absorption and reflectance features (Table 1), whilst, space-borne sensors that traditionally used for geologic remote sensing, like the ASTER and Landsat have only one band in this spectrum (Van der Meer et al., 2014).

In many environments where traditional field surveys are difficult and time-consuming, application of remote sensing methods can separate mineralization based on associated lithological, structural, and hydrothermal alteration types (Eslami et al., 2015; Salaj et al., 2019; Yuanjin et al., 2019; Janati, 2019) and enhance alteration zones. These methods have been used in mineral exploration for delineating structural features that might have controlled mineralization (Ciampalini et al., 2013). Additionally, expansion of hydrothermal fluids and their consequent alterations in PCDs make the remote sensing methods an effective tool for demarcation of hydrothermal alteration zones (Hosseinjani and Tangestani, 2011).

After placing Terra satellite in its orbit, the ASTER multispectral data have extensively been used in mineralogical and lithological studies (Rowan et al., 2003; Özkan et al., 2018; Çörtük et al., 2020). Although important rock-forming minerals (e.g., quartz and feldspar) do not exhibit absorption features in the VNIR and SWIR regions, most of them display fundamental molecular absorption features in the TIR wavelength region (Rowan and Mars, 2003; Mars and Rowan, 2010). The ASTER has limited utility in mapping and characterizing Fe-oxide and Fe-bearing minerals for the absence of blue band that has an absorption feature for iron oxide minerals (Azizi et al., 2010).

Multispectral images including the OLI aboard Landsat-8 and Sentinel-2 have great applications to geological mapping as well as investigation of iron oxide and gossan index minerals (GIM) (Van der Werff, and van der Meer, 2015).

After launching Landsat-8, many papers relevant to this field of research have been published confirming its world while application in mapping of lithology and hydrothermal alteration zones
(Beiranvandpour and Hashim, 2015; He et al., 2015; Çörtük et al., 2020). The Landsat- 8 data can detect the hydrothermal alteration types and iron oxidehydroxide minerals due to the absorption and reflectance characteristics of these minerals through the OLI (Operational Land Imager) sensor with two spectral bands in the shortwave infrared (SWIR) and 5 bands in the visible near infrared (VNIR) (Aryanmehr et al., 2018).

The purposes of the present study are: (i) to perform directed principal component analysis (DPCA) on the Sentinel-2 and Landsat- 8 data to enhance the gossan zones and (ii) to use mixture tuned matched filtering (MTFM) to map hydrothermal alteration halos around copper mineralization zones using the ASTER data, and (iii) to evaluate the obtained results by using each method on the basis of field data and sampling of different hydrothermally altered rocks and gossan zones in a mine scale. The minerals in the collected samples were identified on the basis of X-ray diffraction (XRD) analysis, examination of thin sections, and spectroradiometric analysis.

\section{GEOLOGICAL SETTING AND MINERALIZATION}

The tectonic setting of Urumieh-Dokhtar magmatic belt (UDMB) is similar with the wellknown Andean magmatic belt which comprises many PCDs. It is suggested that the UDMB has also outstanding economic potential especially for porphyry copper mineralization (Alavi, 1994; Aghazadeh et al., 2015). The study area is located within the Central Iranian magmatic belt (the UDMB) in southern part of the Central Iran, southeast of Kerman Province (Fig. 1b). In fact, the area is situated in the Kerman copper district, so called DahejSarduiyeh (Fig. 1a), volcano-sedimentary belt in which various occurrences of copper mineralization including the nation's prestigious PCD (the Sar Cheshmeh) is located. There are certain man-made remains (e.g., tunnels and piles of dumped slag) in the study area which are indicative of a relatively prolonged ancient mining and metallurgical activities carried out by Iranian miners (Dimitrijevic, 1973). The study area is mountainous and poorly-vegetated with a semi-arid climate, and has altitudes varying from $1600 \mathrm{~m}$ to $4174 \mathrm{~m}$ above the sea level (Khaleghi et al., 2014). In the southern part of the study area (southeast of the Kerman magmatic belt) there is a volcanicplutonic complex, so-called Bahr-Aseman. Unlike Kerman magmatic belt which formed and evolved in a dominantly continental arc and post-collision tectonic settings during Eocene in an oceanic islandarc setting (Dimitrijevic, 1973).

The Bahr-Aseman Eocene sequence consists of andesite, andesitic-basalt, basalt, rhyolite, trachyte, trachy-andesite, trachy-basalt and pyroclastic equivalents. The Oligocene-Miocene sedimentary rocks overlie the older Eocene volcanic sequence in the western parts of the area. They consist of a variety 

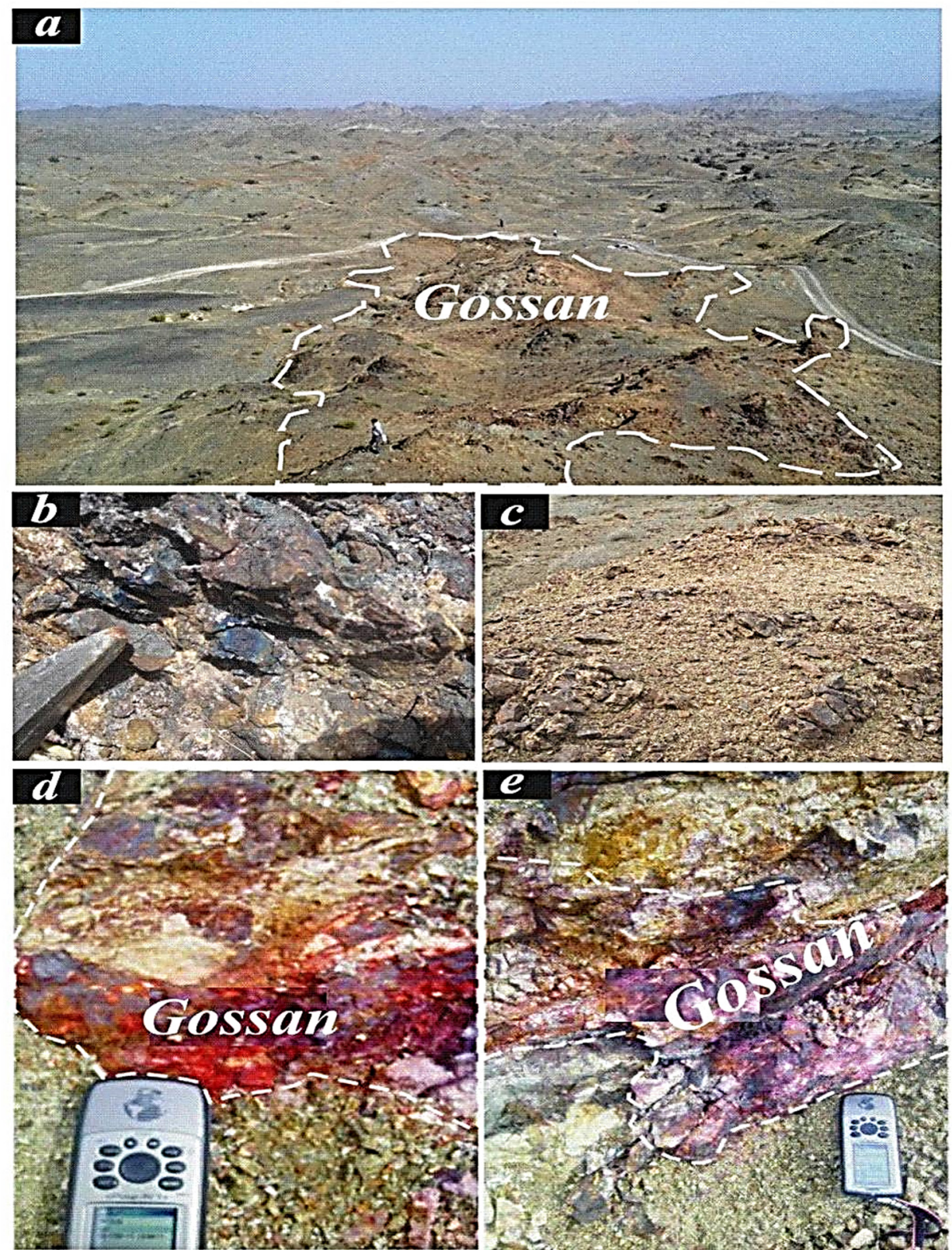

Fig. 2 Field photos from the Zamin-Hossein area. (a) A field view of the gossan zone. (b, c) Close-up and panoramic views of the gossan zone. (d) A close view of patches containing jarosite, hematite, and goethite. (e) A close view of patches beaing hematite and goethite.

of limestones, tuffs, and tuffaceous sandstone. The Eocene sequence is intruded by Oligo-Miocene granodiorite, quartz-diorite, diorite, monzonite, tonalite, and granite (Fig. 1c). The hydrothermal solutions produced the alteration halos and the copper mineralization zones in the study area. The principal types of hydrothermal alterations in the area are argillic, sericitic, and propylitic (Zolnaj et al., 1956; Dimitrijevic, 1973; Khaleghi et al., 2014). Mineralized veins, specifically in the Eocene volcanics, are present within the fault-related silicified zones, which are mineralized by chalcopyrite, pyrite, bornite, and magnetite. Gossans are developed over many of these deposits that are good indicators for exploration of the PCDs (Fig. 2).
There are numerous copper occurrences in the study area. Some of them were exploited in the ancient times. The porphyry-type copper mineralization crops out near the Qanat-Darreh, Zamin-Hossein, and Damaneh villages (Dimitrijevic, 1973). These local names of villages are given to each individual copper mineralization in this area (Fig. 1c).

\section{METHODS OF INVESTIGATION}

The ASTER has three optical subsystems: the visible and near-infrared (VNIR), shortwave-infrared (SWIR), and thermal infrared (TIR) radiometers (see Table 1). The VNIR and SWIR bands have sufficient resolution to define distinct spectral shapes for carbonate, hydrate- and hydroxyl-bearing sulfate, 
Table1 Characteristics of ASTER, Landsat 8 and Sentinel-2 data (Abrams, 2000; Van der Werff and Van der Meer, 2016; Van der Meer et al., 2014).

\begin{tabular}{|c|c|c|c|c|}
\hline & Landsat $8(\mathrm{OLI})$ & ASTER & Sentinel-2A \\
\hline & & 11 & 14 & 12 \\
\hline \multicolumn{2}{|c|}{ Swath (km) } & 185 & 60 & 290 \\
\hline \multirow{4}{*}{ 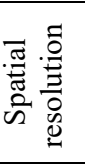 } & VNIR & 30 & 15 & $10-60^{*}$ \\
\hline & SWIR & 30 & 30 & 20 \\
\hline & TIR & 100 & 90 & - \\
\hline & PAN & 15 & - & - \\
\hline \multicolumn{5}{|c|}{ Bandspectral $(\mu \mathrm{m})$} \\
\hline \multicolumn{2}{|c|}{1} & $0.433-0.453$ & $0.52-0.60$ & $0.433-0.453$ \\
\hline \multicolumn{2}{|c|}{2} & $0.450-0.515$ & $0.63-0.69$ & $0.457-0.522$ \\
\hline \multicolumn{2}{|c|}{3} & $0.525-0.600$ & $0.78-0.86$ & $0.542-0.577$ \\
\hline \multicolumn{2}{|c|}{4} & $0.630-0.680$ & $1.600-1.700$ & $0.650-0.680$ \\
\hline \multicolumn{2}{|c|}{5} & $0.845-0.885$ & $2.145-2.185$ & $0.679-0.718$ \\
\hline \multicolumn{2}{|c|}{6} & $1.560-1.660$ & $2.185-2.225$ & $0.732-0.747$ \\
\hline \multicolumn{2}{|c|}{7} & $2.100-2.300$ & $2.235-2.285$ & $0.773-0.793$ \\
\hline \multicolumn{2}{|c|}{8} & $0.500-0.680$ & $2.295-2.365$ & $0.784-0.899$ \\
\hline \multicolumn{2}{|c|}{9} & $1.360-1.390$ & $2.360-2.430$ & $0.855-0.885$ \\
\hline \multicolumn{2}{|c|}{10} & $10.60-11.19$ & $8.125-8.475$ & $0.935-0.955$ \\
\hline \multicolumn{2}{|c|}{11} & $11.50-12.51$ & $8.475-8.825$ & $1.36-1.39$ \\
\hline \multicolumn{2}{|c|}{12} & & $8.925-9.275$ & $1.565-1.655$ \\
\hline \multicolumn{2}{|c|}{13} & & $10.25-10.95$ & $2.10-2.28$ \\
\hline \multicolumn{2}{|c|}{14} & & $10.95-11.65$ & \\
\hline
\end{tabular}

silicate, and other minerals which contain significant SWIR absorption capacities (Table 1). The six individual ASTER scenes (SWIR) bands used in this research are cloud-free level 1B images (acquisition dates: 12 August 2001). The ASTER satellite imageries were corrected for crosstalk effects using the tools provided by ERSDAC (http://gds.aster.ersdac.jspacesystems.or.jp/gds www2002/service e/u.tools e/set u.toole.html). This correction was carried out in order to reduce the SWIR crosstalk effect, which is caused by dispersion of the incident light of the band 4 detector on other detectors in the SWIR region (Honarmand et al., 2012). ASTER level 1B was converted to surface reflectance using fast line of sight atmospheric analysis of spectral hypercubes (FLAASH) software. This technique is initially based on the standard equation of spectral radiance for each pixel of the sensor, which applies to the range of wavelengths of solar radiation (thermal emission is omitted) and a Lambertian and flat surface or their equivalents. It considers the radiance reflected from the Earth's surface and scattered by the atmosphere towards the sensor (Pablito et al., 2016).

The Sentinel-2A satellite is a product of European Space Agency (ESA) which was launched on $23^{\text {rd }}$ of June 2015. The Sentinel-2 mission is an earth observation system which provides high resolution multispectral data with a short revisiting time. This polar-orbiting platform has a sensor with 13 spectral bands in 0.443 to 2.190 micrometers in VNIR and SWIR regions (see Table 1) and spatial resolutions of 10-60 m (European Space Agency 2010). Since bands 1, 9, and 10 are designed for atmospheric corrections (Drusch et al., 2012), Sentinel-2 images were acquired from the European Space Agency (ESA) website. The acquisition time for these images is $5 / 12 / 2016$. For pre-processing of the Sentinel-2 images, geometric correction was also applied using the Sentinel Application Platform (SNAP) computer software which was developed by European Space Agency (ESA).

The Landsat-8, carrying the OLI and the thermal infrared sensor (TIRS), was launched on 4 February 2013 (Roy et al., 2014). The optical bandwidths of the Landsat- 8 are narrower than those of the Landsat-7. Therefore, the Landsat- 8 is expected to improve the quality of mapping for gossan zones and to have strong absorption in near shortwave infrared (SWIR). Table 1 shows the characteristics of Landsat 8 images. OLI images were acquired from the United States Geological Survey (USGS) website. The acquisition date was 9/4/2013. They were converted into reflectance using internal average relative reflectance (IARR). All the satellite images were geometrically corrected using ground control points from the corrected image using image to image geometrical correction.

\subsection{SPECTRAL CHARACTRESTICS OF GOSSAN IN RELATION TO THE LANDSAT-8 AND SENTINEL-2}

Given the spatial extension of the gossan zones and their importance in mineral exploration, sampling of the gossan zones was performed and the spectra of individual gossan index minerals (GIM) such as goethite, jarosite, and hematite were obtained by using 

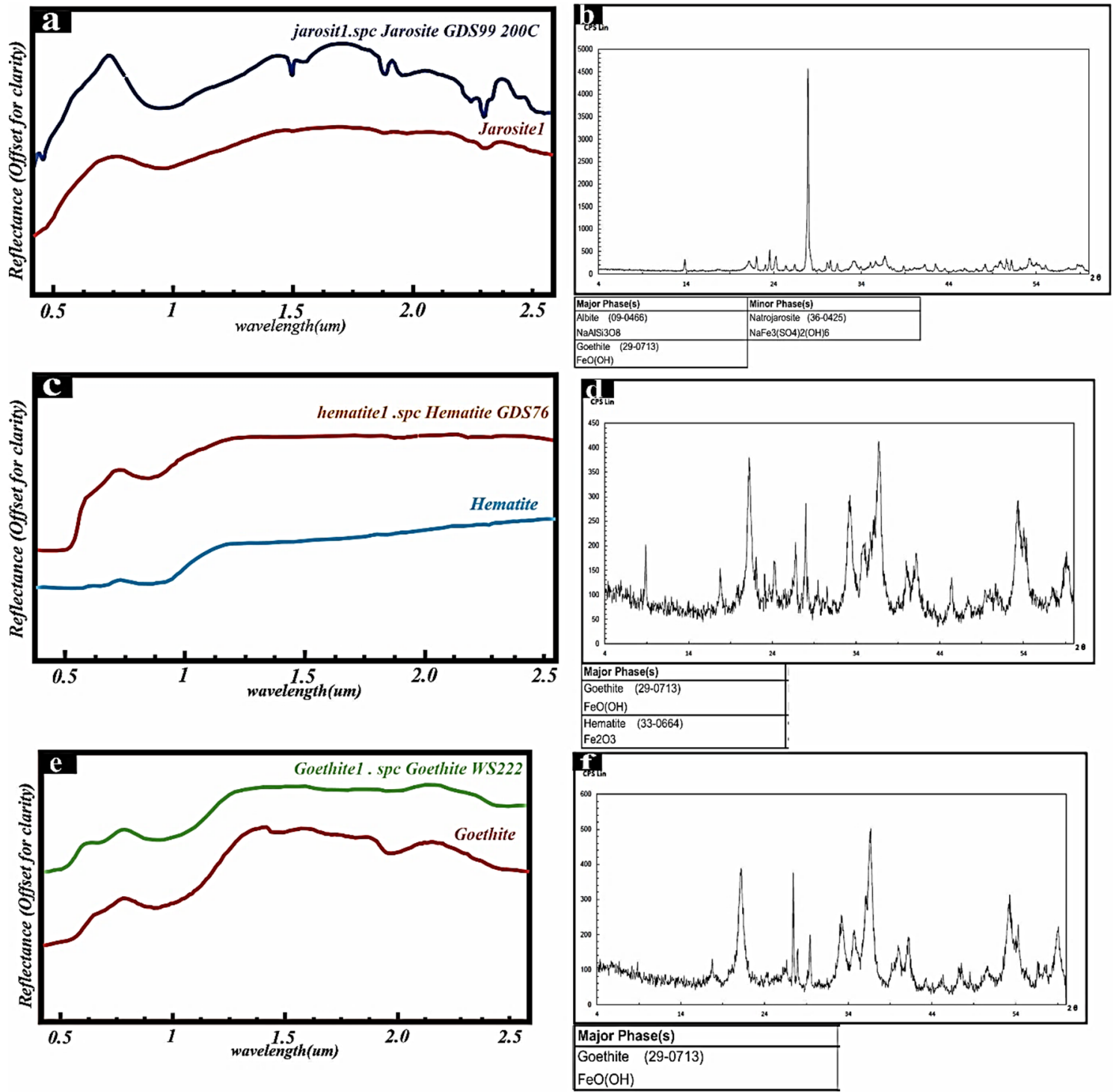

Fig. 3 (a) Comparison of spectral librar y with spectra measurmed in the laboratory from jarosite mineral. (b) XRD pattern of a rock sample from the gossan zone displaying the peaks of goethite and natrojarosite. (c) Comparison of spectral library with spectra measurmed in the laboratory from hematite mineral. (d) XRD pattern of a rock sample from the gossan zone displaying the peaks of hematite $\left(\mathrm{Fe}_{2} \mathrm{O}_{3}\right)$. (e) Comparison of spectral library with spectra measurmed in the laboratory from goethite mineral. (f) XRD pattern of a rock sample from the gossan zone displaying the peaks of goethite $(\mathrm{FeOOH})$.

a Fieldspec3 spectrophotometer. These spectra were matched to the USGS spectral library minerals (Fig. $3 \mathrm{a}, \mathrm{c}, \mathrm{e})$. Then, the comparison between the laboratory and library spectra for the above gossan index minerals (GIM) was made and the spectral reflection and absorption for goethite, jarosite, and hematite were measured to be within the range of $0.5-0.7 \mu \mathrm{m}$.

Considering the obtained spectra, the iron oxiderich parts of the gossan zones were examined by satellite imagery of the Sentinel-2 and Landsat-8. Each of the laboratory mineral spectrum in goethite, jarosite, and hematite was resampled by the Sentinel2 and Landsat- 8 image bands, and their absorption and reflection bands (as a main factor for the bands selection) was applied to the directed principal component analysis (DPCA) method. The absorption and reflection wavelengths of this group of minerals based on the Landsat- 8 and Sentinel- 2 satellites are shown in Figures 4a, b.

Figure 4 (a) shows, the spectra of goethite, jarosite and hematite minerals that were resampled based on the wavelength of Landsat- 8 bands. These minerals show reflections within the spectral range of around 0.65 (Band 4 of the Landsat-8) and absorption within the spectral range of $0.44-0.48$ (Band 2 of the Landsat-8). The resampled goethite, hematite and jarosite minerals (Fig. 4b), on the basis of the Sentinel2 data, show absorption in bands 2 and 3 and reflectance in bands 4 to 6 . 

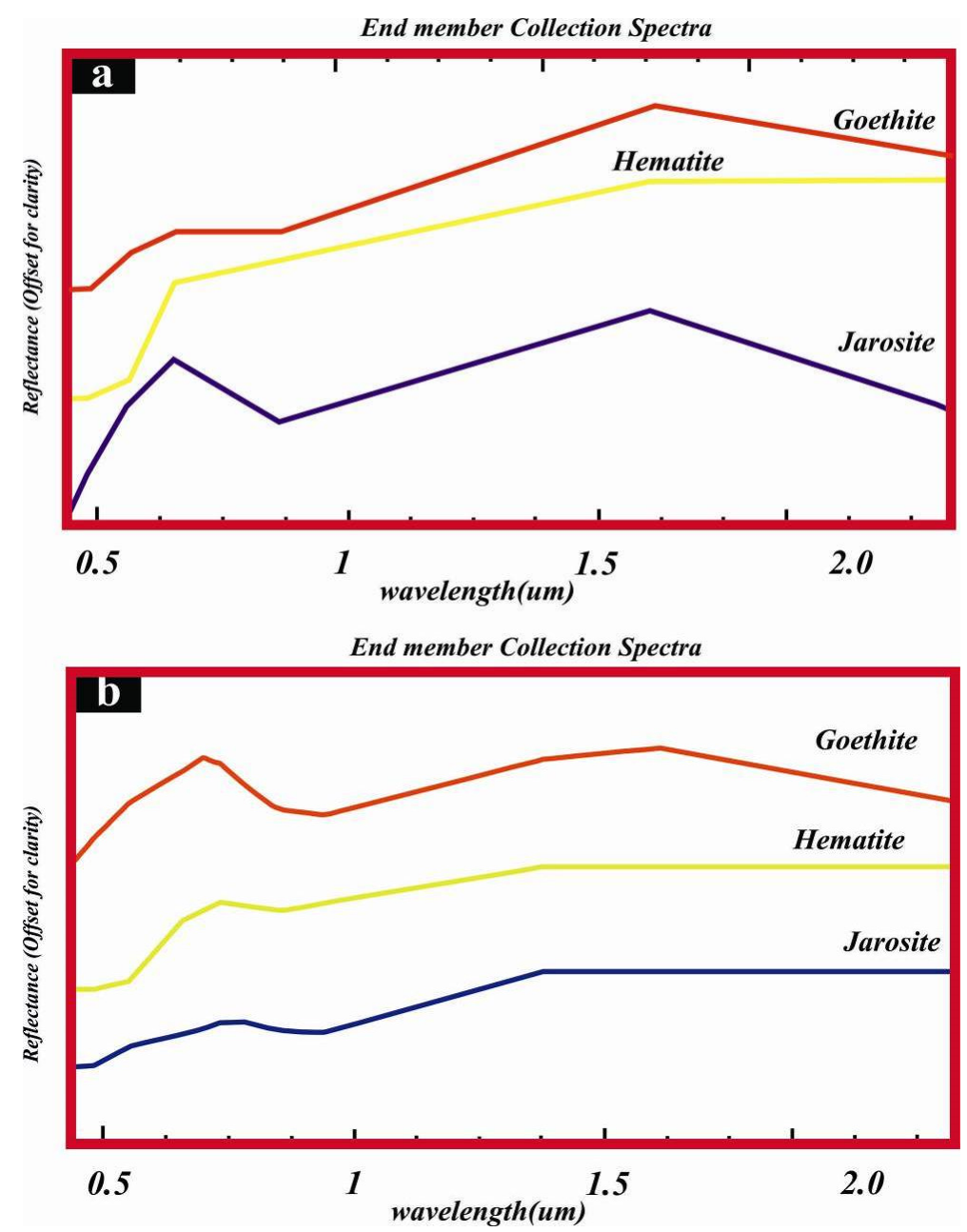

Fig. 4 (a) Re-sampled laboratory spectra of goethite, jarosite, and hematite for the Landsat-8 data. (b) Resampled laboratory spectral of goethite, jarosite and hematite for the Sentinel-2 data.

\subsection{SPECTRAL CHARACTRESTICS OF HYDROTHERMAL ALTERATION IN RELATION WITH THE ASTER}

The hydrothermal alteration is characterized by mineral assemblages which contain at least one mineral that exhibits diagnostic spectral absorption feature (Rowan and Mars, 2006). The VNIR and SWIR spectral regions of the ASTER data are expected to be capable of discriminating the main alteration minerals (Honarmand et al., 2012). As a result, due to the widespread hydrothermal alteration halos in the study area and the experimental spectral data, the hydrothermal alteration minerals were determined on the basis of their characteristics in relation to the ASTER images (Figs. 5a and 5b).

The phyllic zone is characterized by illite/muscovite (sericite) and quartz. Muscovite and illite exhibit an intense Al-OH spectral absorption feature typically centered at $2.20 \mu \mathrm{m}$ (the ASTER band 6, Fig. 5c) and a less intense feature near $2.38 \mu \mathrm{m}$ (the ASTER band-8, Fig. 5c). The argillic zone typically contains kaolinite, alunite, and montmorillonite. Montmorillonite displays an Al-OH absorption feature near $2.20 \mu \mathrm{m}$ (Fig. 5c) (Hunt, 1977; Hunt and Ashley, 1979). In the propylitic zone, mineral assemblage reflectance spectra are characterized by $\mathrm{Fe}, \mathrm{Mg}-\mathrm{OH}$, and $\mathrm{CO}_{3}$ absorption features caused by molecular vibrations in epidote, chlorite. These absorption features lie within the range of 2.33-2.35 $\mu \mathrm{m}$ (the ASTER band 8) (Fig. 5c) (Rowan and Mars, 2006; Rowan et al., 2006).

\subsection{DIRECTED PRINCIPAL COMPONENT ANALYSIS (DPCA)}

The Principal Components Analysis (PCA) transformation is a multivariate statistical technique which selects uncorrelated linear combinations (eigenvector loadings) of variables in such a way that each successively extracted linear combination, or principal component (PC), has a smaller variance (Singh and Harrison, 1985). PCA reduces spectral redundancy in multispectral data, segregates noise components and creates a new set of images that enhanced interest targets based on input bands and their combination in the new PCs (Masoumi et al., 2016). The PCA of image data is computed using three 

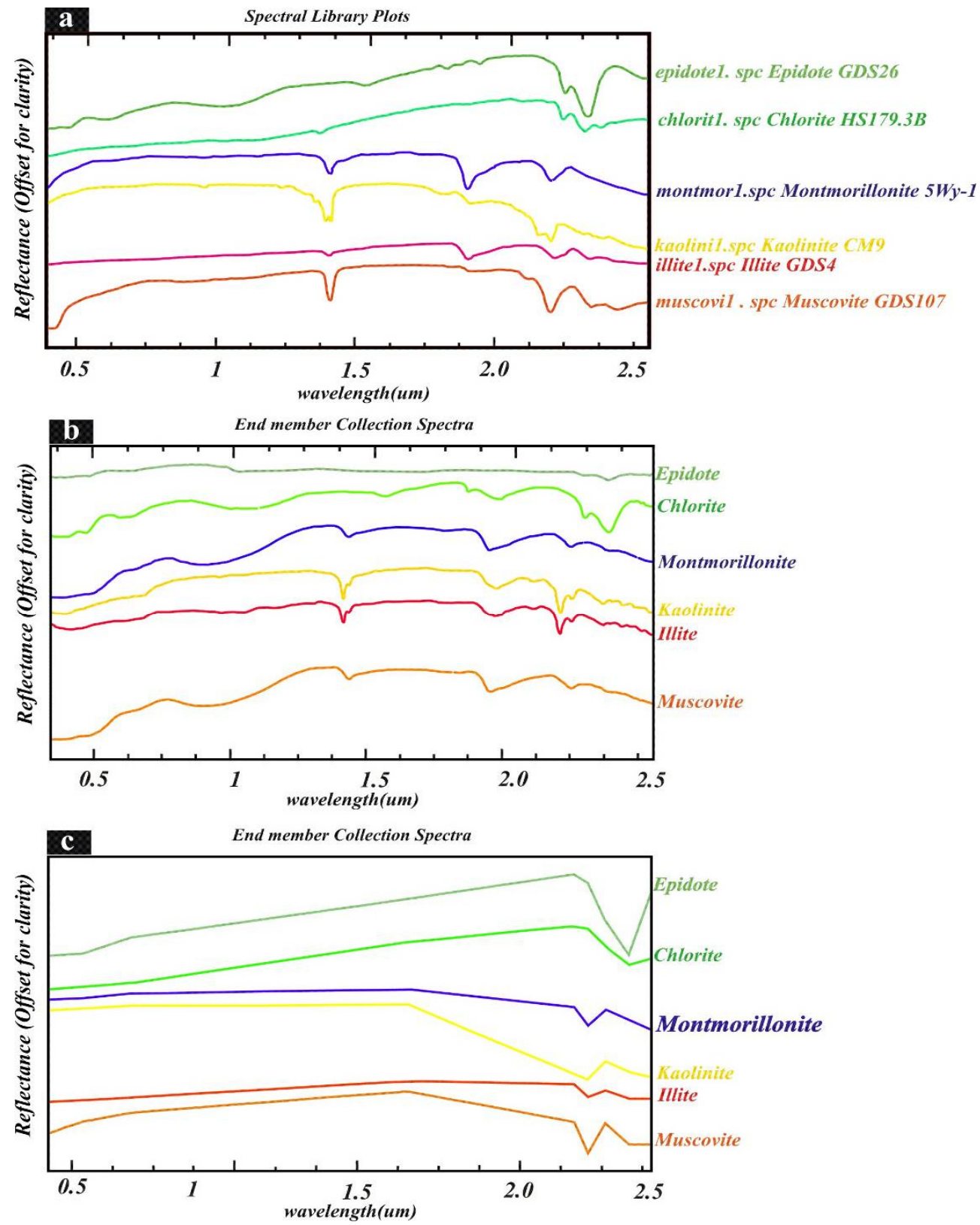

Fig. 5 (a) USGS spectral library plots of minerals such as epidote, chlorite, montmorillonite, kaolinite, illite, and muscovite. (b) Extracted end member (laboratory spectra) for samples from hydrothermal alteration zones. (c) Re-sampled hydrothermal minerals (epidote, chlorite, montmorillonite, kaolinite, illite, and muscovite) by the ASTER data.

steps: (1) calculation of the variance, covariance matrix or correlation matrix of the satellite image data; (2) computation of the eigenvalues and eigenvectors of the variance-covariance matrix or correlation matrix; and (3) linear transformation of the image data using the coefficients of the eigenvector matrix. This well-known method is widely used for mapping hydrothermal alteration zones using the Landsat and Sentinel-2 data (Mia and Fujimitsu, 2012; Corumluoglu et al., 2015; Mokhtari et al., 2015; Guha et al., 2015; Masoumi et al., 2017). In the directed PCA (DPCA) that is so called Crosta method, only selected bands are chosen which contain absorption and reflection features for the minerals under investigation. If the number of input channels is reduced to avoid a particular spectral contrast, the chances of defining a unique principal component for a specific mineral class will be increased (RuizArmenta and Prol-Ledesma 1998). It is expected that the PC image that collects moderate to high eigenvector loadings for the diagnostic absorptive and reflective bands of the index mineral could be considered as the specific image for that mineral. If the loading of absorptive band is positive in sign, the target area will be enhanced in bright pixels, and if the loading of reflective band is negative, the area will be enhanced in dark pixels (Crosta and Moore, 1989). 
Table 2 Eigenvector loadings for the three bands combination of the Landsat- 8 .

\begin{tabular}{lcrrr}
\hline & PC1 & PC2 & PC3 & Mineral \\
\hline Band 4 & 0.36 & 0.13 & 0.92 & goethite \\
\hline Band 5 & 0.49 & -0.87 & -0.07 & \\
\hline Band 6 & 0.80 & 0.48 & -0.38 & \\
\hline \% of variance & 89.57 & 7.25 & 3.17 & jarosite \\
\hline Band 3 & 0.27 & -0.01 & 0.96 & \\
\hline Band 5 & 0.51 & -0.85 & -0.15 & \\
\hline Band 6 & 0.82 & 0.53 & -0.23 & hematite \\
\hline Band variance & 72.44 & 21.39 & 6.15 & \\
\hline Band 3 & -0.38 & -0.79 & 0.47 & \\
\hline Band 4 & -0.56 & -0.21 & -0.78 & 0.36 \\
\hline \% of variance & -0.73 & 0.57 & 0.41 & \\
\hline
\end{tabular}

\subsection{MIXTURE TUNED MATCHED FILTRING}

Several spectral mixture analyses are used for the spectral discrimination of materials in any pixel (Glenn et al., 2005; Mundt et al., 2005). One of the most effective techniques for detecting specific materials differing subtly from their background is the MTMF (Boardman, 1998). The MTMF is an advanced spectral unmixing algorithm in which it is unnecessary for all materials within a scene to be known or to have identified endmembers (Boardman et al., 1995), and it combines the best aspects of the linear spectral mixing model and the statistical matched filter model while avoiding the drawbacks of the original methods. In fact, the MTMF, a special type of spectral mixture analysis, is based on well-known signal processing methodologies and is capable of detecting specific cover types based on their spectral characteristics (Harris and Bryant, 2009). The MTMF method includes three main steps: (1) an MNF transformation of apparent reflection data (Green et al., 1988), (2) matched filtering for abundance estimation, and (3) mixture tuning (MT) to identify infeasible or falsepositive pixels (Boardman, 1998). The output of MTMF is a set of rule images given as MF and infeasibility scores for each pixel related to each endmember.

\section{RESULTS}

\subsection{DIRECTED PRINCIPAL COMPONENT ANAL YSIS (DPCA)}

In the DPCA method, the data of the Landsat- 8 and Sentinel-2 were used for mapping of the gossan index minerals such as goethite, jarosite and hematite around Zamin Hossein and other PCDs. Table 2 lists the result of the DPCA eigenvector loadings of three Landsat- 8 bands. The Landsat- 8 bands 4,5 and 6 were used in the DPCA because they define the $\mathrm{Fe}-\mathrm{OH}$ reflection and absorption features. The PC3 defines the goethite mineral because it contains a positive loading for band $4(0.92)$ and negative loading for absorption bands $5(-0.07)$ and $6(-0.38)$ (Fig. 6a). For jarosite bands 6, 5 and 3 were used. PC2 enhances jarosite (Fig. 8a), while for hematite PC2 with positive and higher loading of band 4 is used (Fig. 7a).

According to the eigenvector loadings on the three Sentinel-2 bands (Table 3), bands 7-3 and 2 were used in the DPCA as they explain the goethite reflection and absorption features (Fig. 6b). The PC2 has positive loading for band $7(0.58)$ and negative loading for bands $3(-0.55)$ and $2(-0.59)$. Jarosite shows a positive loading for band $5(0.64)$ and negative loadings for band $3(-0.49)$ and band $2(-0.59)$ in PC2 (Fig. 8b). Hematite shows a positive loading for band 2 (0.94), which is the absorption band, and negative loadings for band $5(-0.11)$ and band $6(-0.31)$. These bands are the reflection bands for hematite. Therefore, inverse of PC2 is enhancing hematite bearing areas (Fig. 7b). Some of these outcrops where investigated in the field and samples were collected for further mineralogical investigations. XRD analysis of the samples from the gossan zones have shown goethite, hematite and jarosite as major phases (Figs. 6e, 7e, 8e). The obtained results from the XRD analysis can be correlated with the results of spectral analysis (Figs. 6d, 7d and 8d). In addition, on the basis of petrography observation (Figs. 6c, 7c and 8c) and collected sample from the gossan zone indicate the gossan index minerals (GIM) that correlated with spectral analysis results (Figs. 6b, 7b and 8b).

\subsection{MIXTURE TUNED MATCHED FILTERING}

Mixture tuned matched filtering method was selected and applied to (VNIR+SWIR) band of the ASTER to identify hydrothermal alteration zones associated with the Known porphyry copper deposit in the study area. The results of the MTMF are presented as two sets of gray images for each end member including the MF image score and the infeasibility image. The MF image provides a means for estimating relative degree of match to the reference spectrum and the approximate subpixel abundance ranging in value 

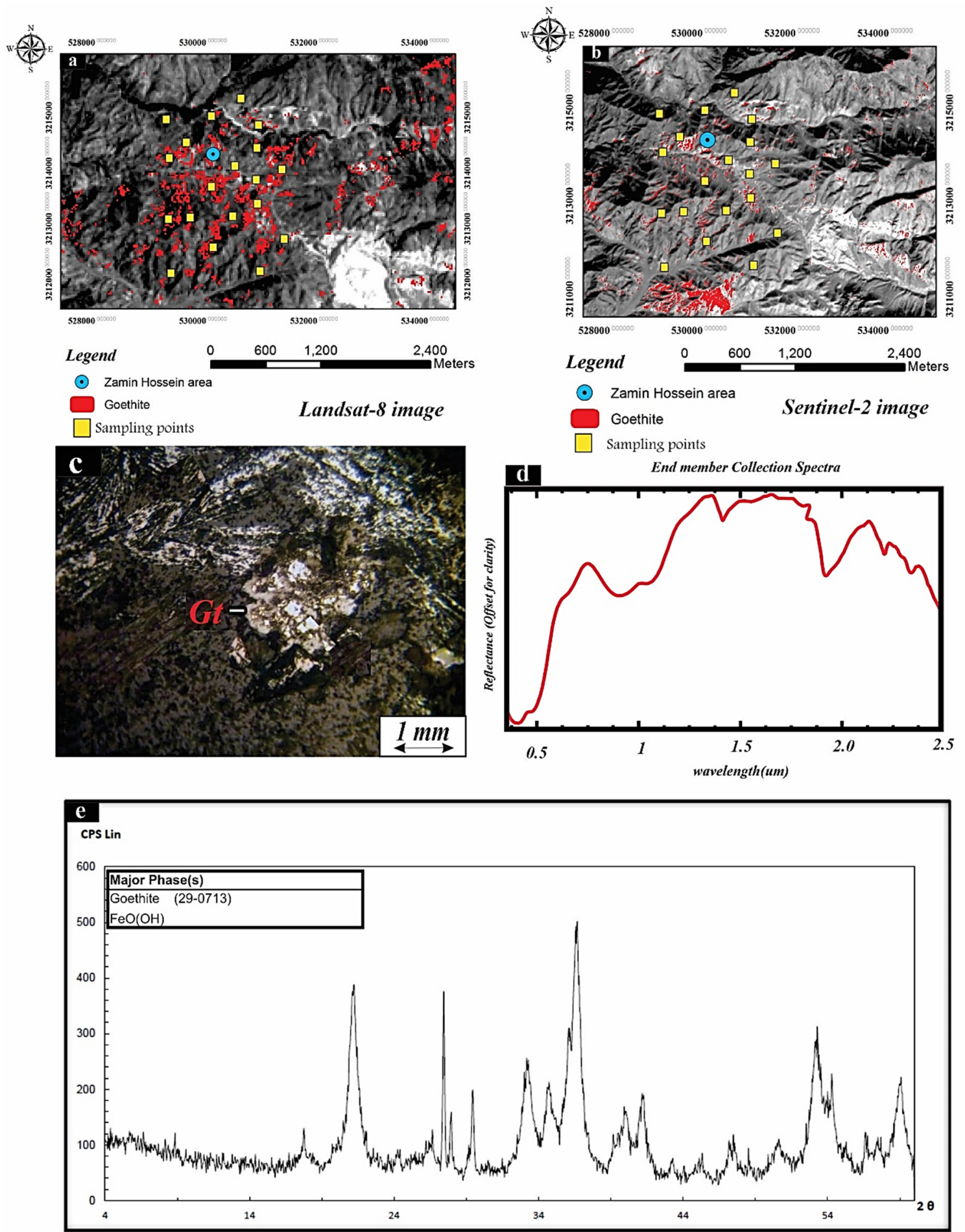

Fig. 6 (a, b) The PC3 (see Tables 2 and 3) images showing the distribution of goethite on the Landsat-8 (a) and the Sentinel-2 (b). (c) Photomicrograph of goethite collected from an outcrop of the gossan zone in the Zamin-Hossein area. (d) Field Spectra of goethite collected from a sample from the gossan zone. (e) XRD pattern of a rock sample from the gossan zone displaying the peaks of goethite (FeOOH).

from 0 to 1.0 (Hosseinjani Zadeh et al., 2014). In this technique, we used the spectra of the samples collected from the phyllic, argillic, and propylitic alteration zones (Figs. 9b, 10b, and 11b) characterized by some index minerals such as illite-muscovite, kaolinitemontmorillonite, and epidote- chlorite at ZaminHossein. These zones were enhanced by the MTMF method. The frequency of the index minerals in each of the alteration zones in this method varied from 0 to 1 (Figs. 9a, 10a, and 11a). The spectra obtained by this group of minerals along with the results of XRD analysis show that field indications are consistent with the spatial distribution of the mapped hydrothermal alteration zones. The XRD analysis of the collected samples show that altered samples contain albite and montmorillonite (Fig. 9e, the 

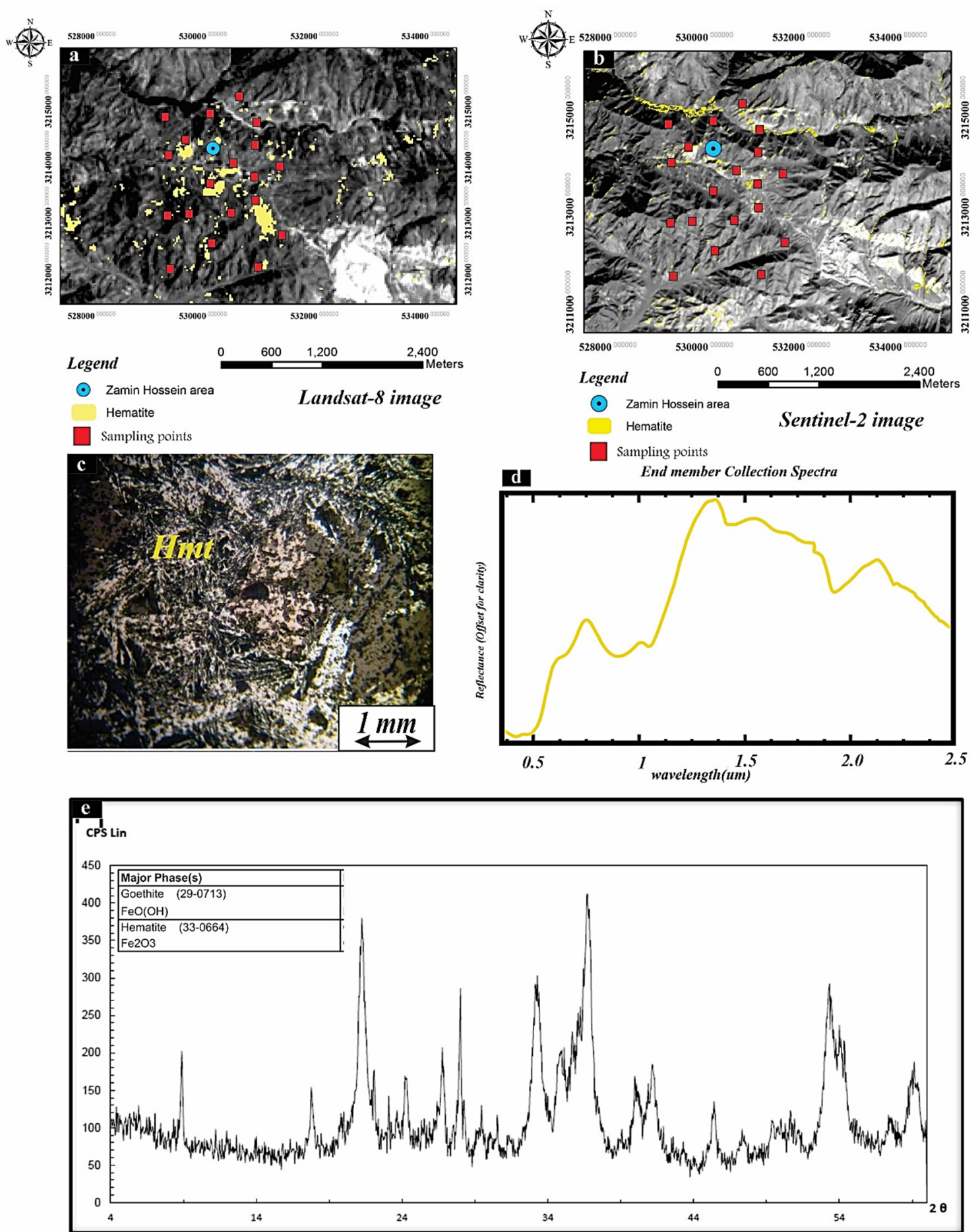

Fig. 7 (a, b) The PC3 (see Tables 2 and 3) images displaying the distribution of hematite on the Landsat-8 (a) and the Sentinel-2 (b). (c) Photomicrograph of hematite collected from an outcrop of the gossan zone in the Zamin-Hossein area. (d) Field Spectra of hematite obtained from a sample from the gossan zone. (e) XRD pattern of a rock sample from the gossan zone illustrating the peaks of hematite $\left(\mathrm{Fe}_{2} \mathrm{O}_{3}\right)$ and goethite (FeOOH).

argillic zone), muscovite and illite (Fig. 10e, the phyllic zone) and chlorite/epidote and calcite (Fig. 11e, the propylitic zone). These results are in agreement with the spectra measured from the respective alteration zone (Figs. 9d, 10d and 11d).

\section{DISCUSSION}

Spatial distribution of hydrothermal alteration zones in the study area were mapped by applying the MTMF method using the ASTER data. The spatial zonation of hydrothermal alteration halos displays an intensive sericitic (illite and muscovite) in the center, 
Table 3 Eigenvector loadings for the three bands combination of the Sentinel-2.

\begin{tabular}{lrrrc}
\hline & PC1 & PC2 & PC3 & Minerals \\
\hline Band 2 & -0.34 & -0.59 & -0.72 & goethite \\
\hline Band 3 & -0.48 & -0.55 & 0.68 \\
\hline Band 7 & -0.81 & 0.58 & -0.09 \\
\hline \% of variance & 96.27 & 3.51 & 0.22 & \\
\hline Band 2 & -0.38 & -0.59 & -0.71 \\
\hline Band 3 & -0.53 & -0.49 & 0.69 \\
\hline Band 5 & -0.75 & 0.64 & -0.13 \\
\hline \% of variance & 96.89 & 2.85 & 0.24 & jarosite \\
\hline Band 2 & 0.31 & 0.94 & 0.12 \\
\hline Band 5 & 0.64 & -0.11 & -0.75 & hematite \\
\hline Band 6 & 0.69 & -0.31 & 0.64 & \\
\hline \% of variance & 98.02 & 1.74 & 0.22 & \\
\hline
\end{tabular}

argillic (kaolinite and montmorillonite) and propylitic (epidote and chlorite) in the peripheral parts of the hydrothermal alteration halos. The Zamin-Hossein intrusive body is located at the center of these alteration halos. The spectra of the index minerals of each hydrothermal alteration type used in this algorithm and the abundance of each mineral in the MTMF image varied within the ranges of 34-54, 54- 74 and 74-100 percent. Among the three spectral data (USGS spectral library, image derived spectra, and laboratory spectra) the laboratory spectra provided better maps for the hydrothermal alteration zones as compared with the conventional field map. The mapped hydrothermal alteration zones were investigated in the field and representative samples were collected from the outcrops. The samples analyzed through spectral analysis showed the typical absorptions for the alteration minerals. The results of the spectral analysis were verified by XRD analysis and petrographical investigation (Figs. 9, 10 and 11). Although the clay minerals cannot be recognized through the petrographical examination, but other minerals such as sericite (muscovite), chlorite/epidote and calcite can be recognized in the thin sections (Figs. 9c, 10c and 11c).

Also, due to the extent and importance of the gossan zones in the study area, the Landsat- 8 and Sentinel-2 images were used to map the minerals such as goethite, hematite and jarosite that belong to the gossan zone. To better identify the gossan zones (Jarosite, goethite, and hematite), the data obtained by Sentinel-2 and Landsat- 8 were compared using the DPCA method (Tables 2 and 3). The spectral bands were chosen based on the examination of individual mineral spectral properties of jarosite, goethite, and hematite. According to the PCA analysis, the Sentinel2 data provides more accurate representation relative to the field surveys carried out earlier. Because the Sentinel-2 data compared to the Landsat-8, has a better spatial and spectral resolution. The results thus obtained were checked by field surveys and sampling. The argillic and phyllic hydrothermal alteration zones are overlain by gossan zones in some parts of the study area. The zones which contain both hydrothermal alteration and gossan cap, have more potential for copper mineralization, as the sulfide minerals are oxidized and have been washed to the supergene zone. This vertical zonation (oxide, supergene and hypogene zones) is observed in the well-known porphyry copper deposits such as Sar Cheshmeh, Darrehzar and Meiduk within the central Iranian volcanic belt. The image processing of the satellite data was verified by petrographic examination of the thin sections, results of X-ray diffraction (XRD) analysis, and the laboratory spectral analysis (Figs. 6, 7 and 8).

The analysis of samples collected from the surface outcrops of the hydrothermal alteration zones and from the diamond drill cores showed that copper mineralization took place predominantly at the contact of the phyllic and argillic alteration zones and magnetite mineralization occurred chiefly in the propylitic zone. In fact, copper mineralization is conspicuously observed in localities where the phyllic and argillic alteration zones have relatively high iron oxides. The geological setting, hydrothermal alteration pattern that is mapped by satellite images, presence of the gossan zone, mineralogical composition and the vertical variation of copper content suggest a porphyry type mineralization for Zamin Hossein area.

\section{CONCLUSIONS}

1. The Sentinel -2 data proved to provide remarkably better mapping for iron oxide minerals than the OLI and ASTER data.

2. The copper mineralization occurred predominantly at the contact of the argillic and phyllic hydrothermal alteration zones which contain relatively higher Fe-oxide content. This occurrence was enhanced by using both the DPCA and MTMF methods. The diamond drill cores data indicate that copper is more enriched below the gossan zones.

3. The use of spectra obtained from hydrothermal alteration minerals in the laboratory and applying the MTMF method depicts that the alteration 

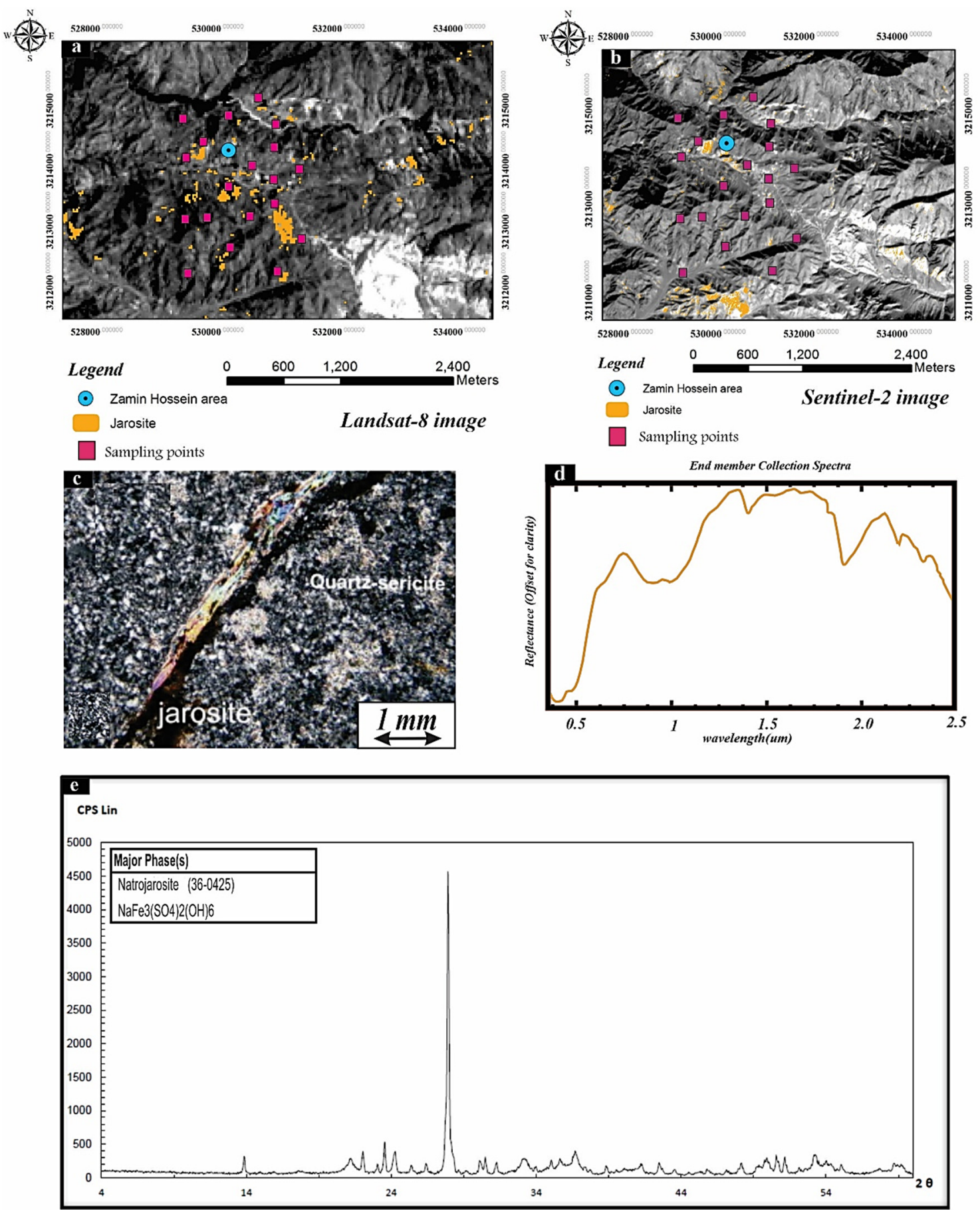

Fig. 8 (a, b) The PC2 (see Tables 2 and 3) images depicting the distribution of jarosite on the Landsat-8 (a) and the Sentinel-2 (b). (c) Photomicrograph of jarosite collected from an outcrop of the gossan zone in the Zamin-Hossein area. (d) Field Spectra of jarosite obtained from a sample from the gossan zone. (e) XRD pattern of a rock sample from the gossan zone displaying the peaks of jarosite.

minerals were detected more accurately relative to those images that are derived from standard spectral libraries.

4. The hydrothermal alteration pattern and the distribution of the gossans in the area show a porphyry-type mineralization.

5. This study showed that the synergetic use of different satellite images with different spatial and spectral resolutions can be used for mineral exploration in a large scale.

\section{ACKNOWLEDGMENTS}

This manuscript was benefited from the comments of two anonymous reviewers. This work was supported financially by the Research Bureau of Urmia University. The authors would like to express their thanks to the authorities of the institute of Science and high Technology and Environmental Science, Graduate University of Advanced Technology in Kerman for spectral measurements of the studied samples. 


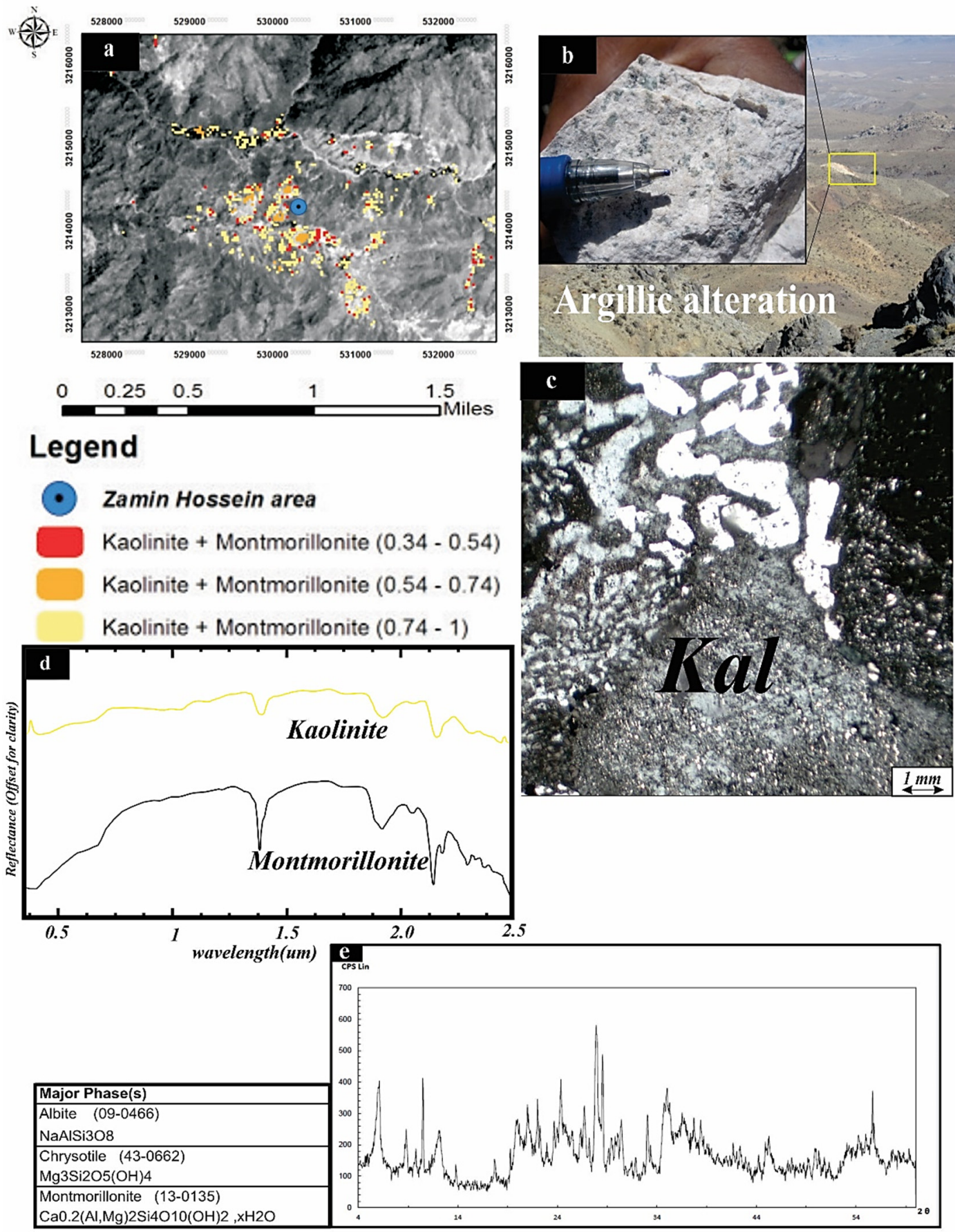

Fig. 9 (a) Enhanced argillic alteration zones on the ASTER image. (b) A field view and close-up photos of the argillic alteration zone in the study area. (c) Photomicrograph of kaolinite collected from an outcrop of the argillic zone at Zamin-Hossein. (d) Field spectra of kaolinite and montmorillonite minerals obtained from the argillic zone. (e) XRD pattern of a rock sample from the argillic zone displaying the peaks of albite and montmorillonite

\section{REFERENCES}

Abrams, M.: 2000, The advanced spaceborne thermal emission and reflection radiometer (ASTER): data products for the high spatial resolution imager on NASA's Terra platform. Int. J. Remote Sens., 21, 847859. DOI: $10.1080 / 014311600210326$

Aghazadeh, M., Hou, Z., Badrzadeh, Z. and Zhou, L.: 2015, Temporal-spatial distribution and tectonic setting of porphyry copper deposits in Iran: constraints from zircon $\mathrm{U}-\mathrm{Pb}$ and molybdenite Re-Os geochronology. Ore Geol. Rev., 70, 385-406.

DOI: $10.1016 /$ j.oregeorev.2015.03.003

Alavi, M.: 1994, Tectonics of Zagros Orogenic belt of Iran, new data and interpretation. Tectonophysics, 229, 211-238. DOI: 10.1016/0040-1951(94)90030-2 


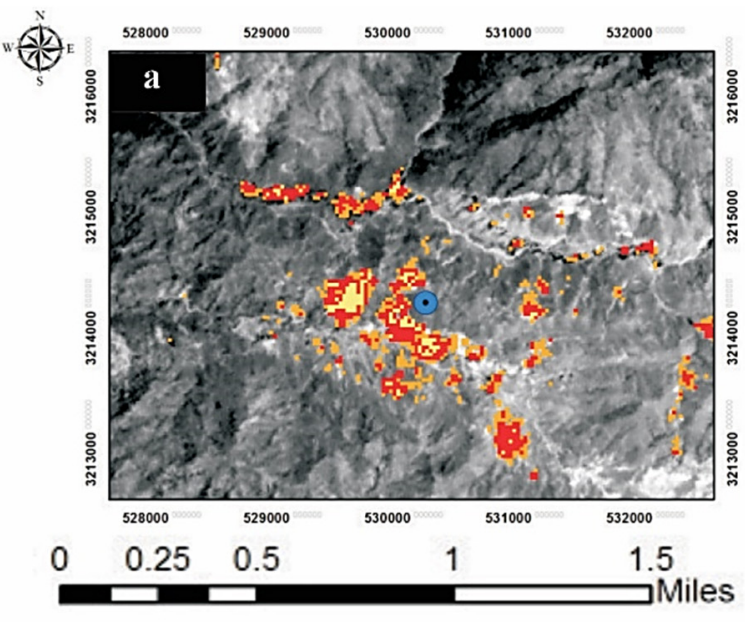

\section{Legend}
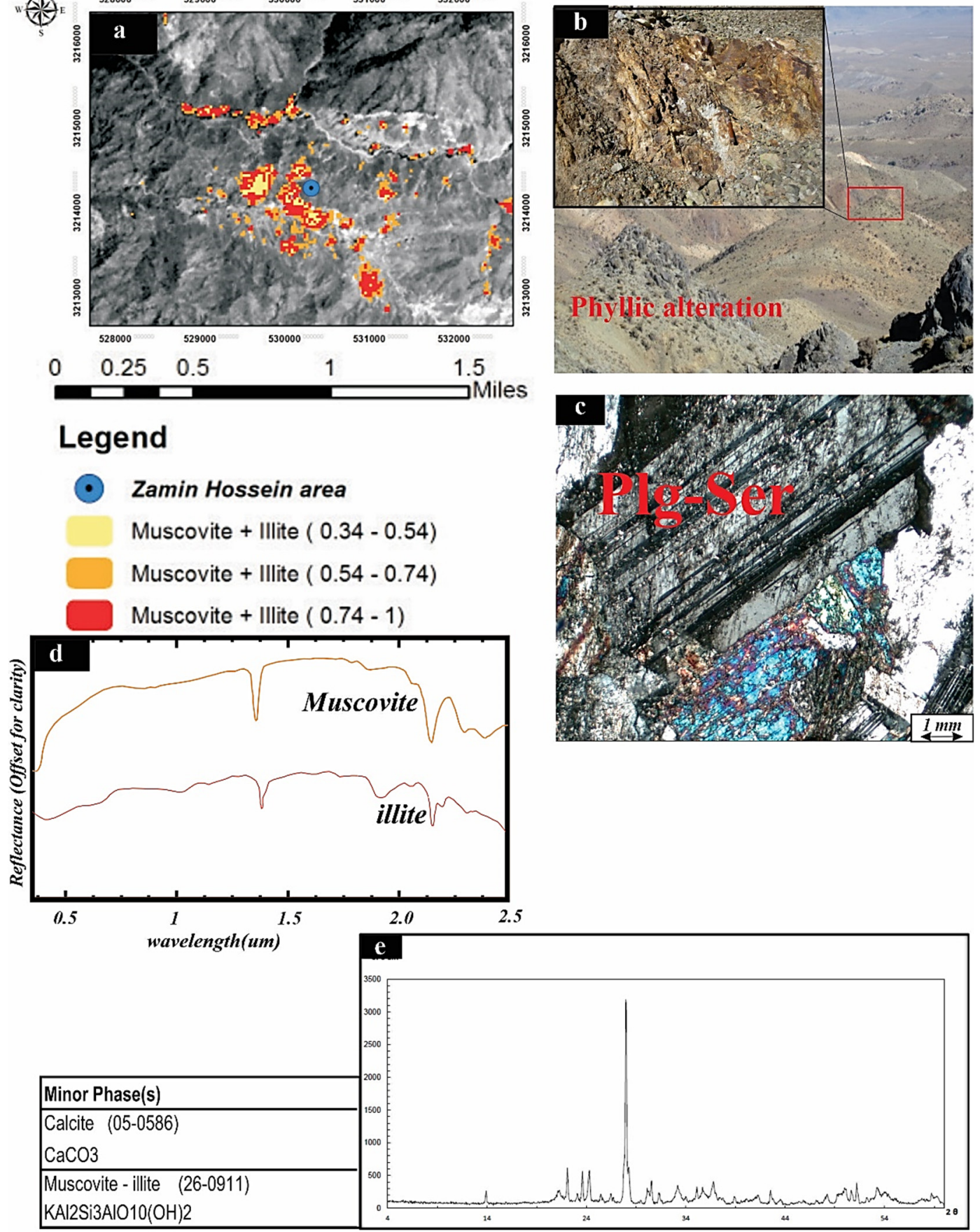

Fig. 10 (a) Enhanced phyllic alteration zones on the ASTER image. (b) A field view and close-up photos of the phyllic alteration zone in the study area. (c) Photomicrograph of muscovite and illite collected from an outcrop of the phyllic zone at Zamin-Hossein. (d) Field spectra of muscovite and illite minerals obtained from the phyllic zone. (e) XRD pattern of a rock sample from the phyllic zone displaying the peaks of muscovite and illite.

Aryanmehr, H., Hosseinjani Zadeh, M., Honarmand, M. and Naseri, F.: 2018, Hydrothermal alteration mapping using Quickbird and landsat-8 data, a case study from Babbiduyeh, Kerman province, Iran. J. Min. Environ., 9, 41-52. DOI: 10.22044/jme.2017.5522.1364

Atapour, H. and Aftabi, A.: 2007, The geochemistry of gossans associated with Sarcheshmeh porphyry copper deposit; Rafsanjan. Kerman, Iran: implications for exploration and the environment. J. Geochem. Explor., 93, 47-65.

DOI: $10.1016 /$ j.gexplo.2006.07.007

Azizi, H., Tarverdi, M.A. and Akbarpour, A.: 2010, Extraction of hydrothermal alterations from ASTER SWIR data from east Zanjan, northern Iran. Adv. Space Res., 46, 99-109.

DOI: 10.1016/j.asr.2010.03.014 

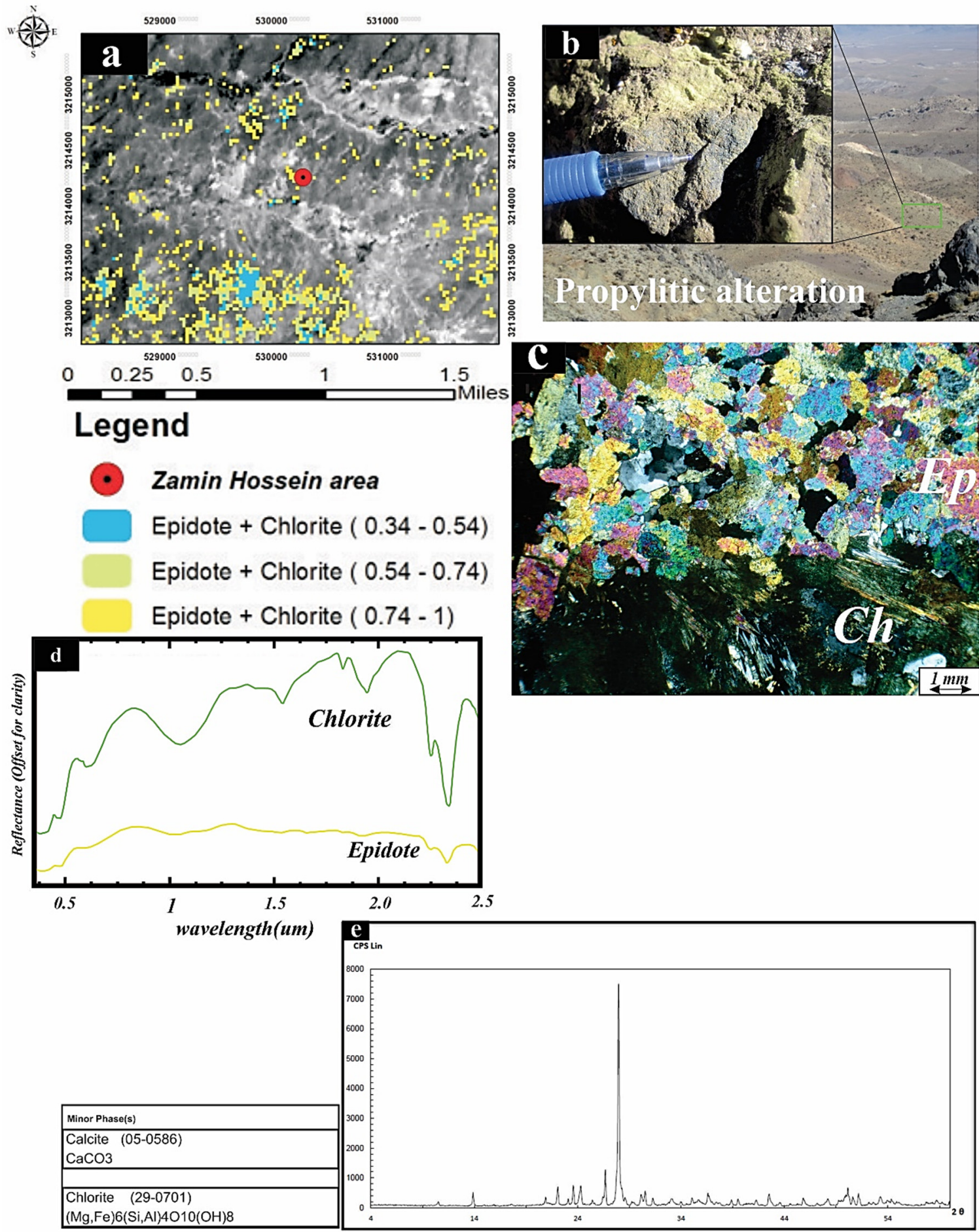

Fig. 11 (a) Enhanced propylitic alteration zones on the ASTER image. (b) A field view and close-up photos of propylitic alteration zone in the study area. (c) Photomicrograph of chlorite and epidote collected from an outcrop of the propylitic zone at Zamin-Hossein. (d) Field spectra of chlorite and epidote minerals obtained from the propylitic zone. (e) XRD pattern of a rock sample from the propylitic zone displaying the peaks of chlorite.

Beiranvandpour, A. and Hashim, M.: 2015, Hydrothermal alteration mapping from Landsat-8 data, Sar Cheshmeh copper mining district, south-eastern Iran. J. Taibah Univ. Sci., 9, 155-166. DOI: $10.1016 /$ j.jtusci.2014.11.008

Boardman, J.W., Kruse, F.A. and Green, R.O.: 1995, Mapping target signatures via partial unmixing of
AVIRIS data: in Summaries. Fifth JPL Airborne Earth Science Workshop, Pasadena. Jet Propulsion Laboratory, 1, 23-26.

Boardman, J.W.: 1998, Leveraging the high dimensionality of AVIRIS data for improved sub-pixel target unmixing and rejection of false positives, mixture tuned matched filtering. Pasadena, CA. Summaries of 
the Seventh Annual JPL Airborne Geoscience Workshop, 55.

Chiaradia, M. and Caricchi, L.: 2017, Stochastic modelling of deep magmatic controls on porphyry copper deposit endowment. Sci. Rep., 7, 1-11.

DOI: $10.1038 /$ srep44523

Çörtük, R.M., Celik, O.F., Alkan, A., Ozkan, M. and Ozyavas, A.: 2020, Distribution of rocks in Pınarbaş1 Ophiolite from central Anatolia (Turkey) based on analysis of ASTER and Landsat-8 data. Geol. J., 1-13. DOI: $10.1002 /$ gj.3844

Ciampalini, A., Garfagnoli, F., Antonielli, B., Moretti, S. and Righini, G.: 2013a, Remote sensing techniques using Landsat ETM+ applied to the detection of iron ore deposits in Western Africa. Arab. J. Geosci., 6, 4529-4546. DOI: 10.1007/s12517-012-0725-0

Corumluoglu, O., Vural, A. and Asri, I.: 2015, Determination of Kula basalts (geosite) in Turkey using remote sensing techniques. Arab. J. Geosci., 8, 10105-10117. DOI: 10.1007/s12517-015-1914-4

Crosta, A.P. and Moore, J.M.: 1989, Enhancement of Landsat Thematic Mapper imagery for residual soil mapping in SW Minais Gerais tate, Brazil: a prospecting case history. In: Greenstone Belt Terrain. Proceedings of the Seventh Thematic Conference on Remote Sensing for Exploration Geology, 2-6 October, Calgary, Canada. ERIM, 1173-1187.

Dimitrijevic, M.D.: 1973, Geology of the Kerman region. Geological Survey of Iran, Tehran, Report No. 52, $334 \mathrm{pp}$.

Drusch, M., Dell Bello, U., Carlier, S., Colin, O., Fernandez, V., Gascon, F., Hoersch, B., Isola, C., Laberinti, P., Martimort, P., Meygert, A., Spoto, F., Sy, O., Marchese, F. and Bargellini, P.: 2012, Sentinel-2: ESA's Optical High-Resolution Mission for GMES Operational Services. Remote Sens. Environ., 120, 25-36. DOI: 10.1016/j.rse.2011.11.026

Eslami, A., Ghaderi, M., Sankaran, R., Beiranvand, A. and Mazlan, H.: 2015, Integration of ASTER and landsat TM remote sensing data for chromite prospecting and lithological mapping in Neyriz ophiolite zone, south Iran. Resour. Geol., 65, 375-388. DOI: $10.1111 /$ rge. 12076

Glenn, N.F., Mundt, J.T., Weber, K.T., Prather, T.S., Lass, L.W. and Pettingill, J.: 2005, Repeat hyperspectral data processing for the detection of small infestations of leafy spurge. Remote Sens. Environ., 95, 399-412. DOI: $10.1016 /$ j.rse.2005.01.003

Green, A.A., Berman, M., Switzer, P. and Craig, M.D.: 1988, A transformation for ordering multispectral data in terms of image quality with implications for noise removal. IEEE Trans. Geosci. Remote Sens., 26, 6574. DOI: $10.1109 / 36.3001$

Guha, A., Ghosh, B., Kumar, V. and Chauhdury, S.: 2015, Implementation of reflection spectroscopy based new ASTER indices and principal components to delineate chromitite and associated ultramafic-mafic complex in parts of Dharwar Craton, India. Adv. Space Res., 56, 1453-1468. DOI: 10.1016/j.asr.2015.06.043

Haris, A. and Brayant, R.G.: 2009, A multi-scale remote sensing approach for monitoring northern peatland hydrology: Present possibilities and future challenges. J. Environ. Manage., 90, 2178-2188. DOI: 10.1016/j.jenvman.2007.06.025

He, J., Harrism J.R., Sawada, M. and Behnia, P.: 2015, A comparison of classification algorithms using
Landsat-7 and Landsat-8 data for mapping lithology in Canada's Arctic. Int. J. Remote Sens., 36, 2252-2276. DOI: 10.1080/01431161.2015.1035410

Honarmand, M., Ranjbar, H. and Shahabpour, J.: 2012, Application of principal component analysis and spectral angle mapper in the mapping of hydrothermal alteration in the Jebal-Barez area, Southeastern Iran. Resour. Geol., 62, 119-139. DOI: $10.1111 / \mathrm{j} .1751-3928.2012 .00184 . \mathrm{x}$

Hosseinjani Zadeh, M. and Honarmand, M.: 2017, A remote sensing - based discrimination of high - and low potential mineralization for porphyry copper deposits; a case study from Dehaj- Sardduieh copper belt, SE Iran. Eur. J. Remote Sens., 50, 332-342.

DOI: $10.1080 / 22797254.2017 .1328646$

Hosseinjani, M. and Tangestani, M.H.: 2011, Mapping alteration minerals using sub-pixel unmixing of ASTER data in the Sarduiyeh area, SE Kerman, Iran. Int. J. Digit. Earth, 4, 485-504. DOI: $10.1080 / 17538947.2010 .550937$

Hosseinjani, M., Tangestani, M.H., Roland, F.V. and Yusta, I.: 2014, Mineral exploration and alteration zone mapping using mixture tuned matched filtering approach on ASTER data at the central part of DehajSarduiyeh Copper Belt, SE Iran. IEEE J. Sel. Top. Appl. Earth Obs. Remote Sens., 7, 284-289.

DOI: $10.1109 /$ JSTARS.2013.2261800

Hunt, G.R.: 1977, Spectral signatures of particulate minerals in the visible and near infrared. Geophysics, 42, 468671. DOI: $10.1190 / 1.1440721$

Hunt, G.R. and Ashley, R.P.: 1979, Spectra of altered rocks in the visible and near infrared. Econ. Geol., 74, 16131629. DOI: 10.2113 /gsecongeo.74.7.1613

Janati, M.: 2019, Application of remotely sensed ASTER data in detecting alteration hosting $\mathrm{Cu}, \mathrm{Ag}$ and $\mathrm{Au}$ bearing mineralized zones in Taghdout area, Central Anti-Atlas of Morocco. J. Afr. Earth Sci., 151, 95106. DOI: $10.1016 /$ j.jafrearsci.2018.12.002

Khaleghi, M., Ranjbar, H., Shahabpour, J. and Honarmand, M.: 2014, Spectral angle mapping, spectral information divergence, and principal component analysis of the ASTER SWIR data for exploration of porphyry copper mineralization in the Sarduiyeh area, Kerman province, Iran. Appl. Geomat., 6, 49-58. DOI: $10.1007 / \mathrm{s} 12518-014-0125-0$

Liu, R. Chen, G. and Yang, J.: 2020, Compositions of Cu(Fe)-sulfides in the 109 reduced granite-related $\mathrm{Cu}$ deposit, Xinjiang, Northwest China: implications to the characteristics of ore-forming fluids. Geofluids, 7391369, 1-11. DOI: 10.1155/2020/7391369

Lowell, J.D. and Guilbert, J.M.: 1970, Lateral and vertical alteration-mineralization zoning in Porphyry Ore deposits. Econ. Geol., 65, 373-408. DOI: 10.2113 /gsecongeo.65.4.373

Mars, J.C. and Rowan, L.C.: 2010, Spectral assessment of new ASTER SWIR surface reflectance data products for spectroscopic mapping of rocks and minerals. Remote Sens. Environ., 114, 2011-2025. DOI: $10.1016 /$ j.rse.2010.04.008

Masoumi, F., Taymour, E., Honarmand, M. and Abkar, A.A.: 2016, A comparative study of Landsat-7 and Landsat- 8 data using image processing methods for hydrothermal alteration mapping. Resour. Geol., 67, 72-88. DOI: $10.1111 /$ rge. 12117 
Masoumi, F., Eslamkish, T., Honarmand, M. and Abar, A.A.: 2017, Utilization of ASTER data and spectral analysis to discriminate hydrothermally altered areas over Rabor, South of Kerman, Iran. J. Indian Soc. Remote Sens., 45, 1039-1055. DOI: $10.1007 / \mathrm{s} 12524-017-0662-1$

Mia, M. and Fujimitsu, Y.: 2012, Mapping hydrothermal altered mineral deposits using Landsat 7 ETM+ image in and around Kuju volcano, Kyushu, Japan. J. Earth Syst. Sci., 121, 1049-1057. DOI: $10.1007 / \mathrm{s} 12040-012-0211-9$

Mokhtari, A.R., Roshani, P., Cohen, D., Emami, A., Dehghanzadeh, A. and Ghegeni, Z.: 2015, Metal speciation in agricultural soils adjacent to the Irankuh $\mathrm{Pb}-\mathrm{Zn}$ mining area, central Iran. J. Afr. Earth Sci., 101, 186-193. DOI: 10.1016/j.jafrearsci.2014.09.003

Mundt, J.T., Glenn, N.F., Weber, K.T., Prather, T.S., Lass, L.W. and Pettingill, J.: 2005, Discrimination of hoary cress and determination of its detection limits via hyperspectral processing and accuracy assessment technique. Remote Sens. Environ., 96, 509-517. DOI: 10.1016/j.rse.2005.04.004

Mwaniki, M.W., Matthias, M.S. and Schellmann, G.: 2015a, Application of remote sensing technologies to map the structural geology of central region of Kenya. IEEE J. Sel. Top. Appl. Earth Obs. Remote Sens., 8, 18551867. DOI: $10.1109 /$ JSTARS.2015.2395094

Özkan, M., Çelik, Ö.F., and Özyavaş, A. 2018, Lithological discrimination of accretionary complex (Sivas, northern Turkey) using novel hybrid color composites and field data. J. Afr. Earth Sci., 138, 75-85. DOI: 10.1016/j.jafrearsci.2017.11.009

Pablito, M., Carlos, A., Juan, G. and Horge, G.: 2016, A comparison of machine learning techniques applied to Landsat-5 TM spectral data for biomass estimation. Can. J. Remote Sens., 42, 690-705. DOI: $10.1080 / 07038992.2016 .1217485$

Rowan, L.C. and Mars, J.C.: 2006, Regional mapping of phyllic- and argillic-altered rocks in the Zagros magmatic arc, Iran, using advanced spaceborne thermal emission and reflection radiometer (ASTER) data and logical operator algorithms. Geosphere, 2,161-186. DOI: 10.1130/GES00044.1

Rowan, L.C., Schmidt, R.G. and Mars, J.C.: 2006, Distribution of hydrothermally altered rocks in the Reko Diq, Pakistan mineralized area based on spectral analysis of ASTER data. Remote Sens. Environ., 104, 74-87. DOI: 10.1016/j.rse.2006.05.014

Rowan, L.C. and Mars, J.C.: 2003, Lithologic mapping in the Mountain Pass, California area using advanced spaceborne thermal emission and reflection radiometer (ASTER) data. Remote Sens. Environ., 84, 350-366. DOI: 10.1016/S0034-4257(02)00127-X

Roy, D.P., Qin, Y., Kovalskyy, V., Vermonter, E.F., Yegorov, J.J. and Hansen, M.C.: 2014, Conterminous United States demonstration and characterization of MODIS-based Landsat ETM+ atmospheric correction. Remote Sens. Environ., 140, 433-449. DOI: $10.1016 /$ j.rse.2013.09.012

Ruiz-Armenta, J.R. and Prol-Ledesma, R.M.: 1998, Techniques for enhancing the spectral response of hydrothermal alteration minerals in Thematic Mapper images of central Mexico. Int. J. Remote Sens., 19, 1981-2000. DOI: 10.1080/014311698215108
Salaj, S.S., Srivastava, S.K., Dugal, R., Upadhyay, R., Suresh Babu, D. and Kaliraj, S.: 2019, Application of ASTER remote sensing for lithological mapping in the Udaipur District of Rajasthan, India. In: Kumar, P., Rani, M., Chandra Pandey, P., Sajjad, H. and Chaudhary, B. (eds), Applications and Challenges of Geospatial Technology. Springer, Cham, 99-119. DOI: 10.1007/978-3-319-99882-4

Singh, A. and Harrison, A.: 1985, Standardized principal components. Int. J. Remote Sens., 6, 883-896. DOI: $10.1080 / 01431168508948511$

Tangestani, M.H. and Shayeganpour, S: 2020, Mapping a lithologically complex terrain using Sentinel-2A data: a case study of Suriyan area, southwestern Iran. Int. J. Remote Sens., 41, 3558-3574. DOI: $10.1080 / 01431161.2019 .1706203$

Van der Meer, F.D., Van der Werff, H.M. and Van Ruitenbeek, F.J.A.: 2014, Potential of ESA's Sentinel2 for geological applications. Remote Sens. Environ., $148,124-133$. DOI: $10.1016 /$ j.rse.2014.03.022

Van der Werff, H. and Van der Meer, F.: 2016, Sentinel-2A MSI and Landsat 8 OLI provide data continuity for geological remote sensing. Remote Sens., 8, 883. DOI: $10.3390 / \mathrm{rs} 8110883$

Yuanjin, X.U., Jianguo, C.H. and Pengyan, M.: 2019, Detection of alteration zones using hyperspectral remote sensing data from Dapingliang skarn copper deposit and its surrounding area, Shanshan County, Xinjiang Uygur autonomous region, China. J. Vis. Commun. Image Represent., 58, 67-78. DOI: $10.1016 /$ j.jvcir.2018.11.032

Zolnaj, S., Timotijevic, S. and Grabeljsek, V.: 1956, Geological map of Iran, 1:100000 Series Sarduiyeh, Geological Survey of Iran, Tehran. Sheet No.7448. 